\title{
Políticas Públicas Educacionais para a Educação Pré-Escolar e as reformulações curriculares de 2016 em Portugal: o caso da Matemática
}

\section{Public Education Policies for Pre-School Education and 2016 curricular reformulations in Portugal: the case of Mathematics}

Políticas Públicas para la Educación para la Educación Pre-escolar y cambios curriculares en 2016 en Portugal: el caso de las Matemáticas

Silvani Kempf Bolgenhagen ${ }^{1}$

Ariana Cosme ${ }^{1}$

DOI: http://dx.doi.org/10.20435/serie-estudos.v24i50.1198

\begin{abstract}
Resumo: Analisou-se a influência das políticas económicas voltadas para a Globalização e o Neoliberalismo sobre o cotidiano Educação Pré-Escolar; os estudos do currículo, sua implementação e repercussão no desenvolvimento no trabalho pedagógico, desde o início da institucionalização da Educação Pré-Escolar até as novas reformulações curriculares (2016). Na busca de validação do tema, foi realizado um levantamento de estudos académicos no Repositório Científico Académico de Portugal, no período de 2006-2016. Desse inventário, foi possível perceber que a grande maioria das pesquisas são referentes às Orientações Curriculares para a Educação Pré-Escolar e as práticas pedagógicas centradas na preocupação do cumprimento do currículo. Para tanto, privilegiam-se os estudos do currículo sobre a educação da infância e as práticas pedagógicas para que se aponta, nomeadamente, sobre a matemática.
\end{abstract}

Palavras-chave: educação; pré-escolar; reforma curricular; Matemática.

\begin{abstract}
We analyze the influence of the economic policies focused on Globalization and Neoliberalism on the daily Pre-School Education; curricular studies, their implementation and development repercussions in the pedagogical work, from the beginning of the institutionalization of PreSchool Education to the new curricular reformulations (2016). In the search for validation of the theme, a study was carried out in the Academic Scientific Repository of Portugal in the period 2006-2016. From this inventory it was possible to perceive that the great majority of the researches are referring to the Curricular Orientations for Pre-School Education and the pedago-
\end{abstract}

\footnotetext{
${ }^{1}$ Universidade do Porto, Portugal.
} 
gical practices centered in the preoccupation of the fulfillment of the curriculum. In order to do so, we focus on studies of the curriculum on the education of children and the teach pedagogical practices, especially on mathematics.

Keywords: education; preschool; curricular reform; Mathematics.

Resumen: Se analizó la influencia de las políticas económicas dirigidas a la Globalización y el Neoliberalismo sobre el cotidiano Educación Pre-Escolar; los estudios del currículo, su implementación y repercusión en el desarrollo en el trabajo pedagógico, desde el inicio de la institucionalización de la Educación Preescolar hasta las nuevas reformulaciones curriculares (2016). En la búsqueda de validación tema, se realizó una encuesta de los estudios académicos en el Repositorio Científico Académico de Portugal en el período 2006-2016. De ese inventario fue posible percibir que la gran mayoría de las encuestas son referentes a las Orientaciones Curriculares para la Educación Preescolar y las prácticas pedagógicas centradas en la preocupación del cumplimiento del currículo. Para ello, se privilegian estudios del currículo sobre la educación de la infancia e las prácticas pedagógicas para que se apunte, en particular sobre las matemáticas.

Palabras-chave: educación; preescolar; reforma curricular; Matemáticas.

\section{INFLUÊNCIAS DAS POLÍTICAS ECONÓMICAS NO ÂMBITO DA EDUCAÇÃO}

Ultimamente as questões que dizem respeito à qualidade da educação da infância tem sido debatidos no campo político educativo. De um certo modo, a expressão "qualidade educacional" (DAVOK, 2007, p. 506) tem repercutido em uma realidade que está sendo posta pelas novas exigências do mercado económico neoliberal, estando este vinculado a uma racionalidade económica e num mundo competitivo. Nesse meio-tempo, a educação se tornou um viés de atendimento a estas demandas, capacitando os estudantes para atenderem o mercado de trabalho e obterem os melhores resultados referentes às suas necessidades nos mais diversos setores do mercado; na visão de Aplle (1998, p. 30), os estudantes são vistos como "capital humano". Nessa esteira, a educação entra como uma opção de produto a ser consumido, ou seja, a educação/escola está vinculada ao mercado de trabalho, tendo que se adequar às novas exigências do mundo neoliberal e globalizado (GIDDENS, 2000; APLLE, 1998).

Essas novas exigências já estão sendo sentidas ao longo dos anos pelas políticas educativas portuguesas, tendo estas que se adaptar a um currículo escolar dentro das convenções educacionais mundiais, por sua vez deixa de lado a "escolha de sociedades individuais no sentido de reunir determinadas condições locais. A definição de conhecimento legítimo para ser ensinado nas escolas e a selecção e organização hierárquica desses corpos de conhecimento são assim cla- 
ramente prescritos externamente" (DALE, 2004, p. 425). As prescrições externas são realizadas pela Organização das Nações Unidas para a Educação, a Ciência e a Cultura (UNESCO), Organização para Cooperação e Desenvolvimento Econômico (OCDE), Banco Mundial, Programa Internacional de Avaliação do Aluno (PISA), entre outros, que buscam a efetividade "da mensagem veiculada pelas organizações internacionais baseadas em modelos, categorias e guiões, das quais o mundo é universalizado e, a um dado nível, unificado, [...]" (DALE, 2004, p. 448).

As avaliações são orientadas segundo as estratégias e metas lançadas pelo PISA, cujos resultados ${ }^{2}$ são orientadores para implementação de políticas públicas educativas. Desse modo, privilegia-se os resultados positivos estabelecidos pelos índices internacionais de qualidade de educação criado pela OCDE, PISA ${ }^{3}$. As avaliações em Portugal, seguem os critérios estabelecidos pelo PISA, as quais apontam uma evolução nos resultados, de maneira positiva, ano a ano, desde o ano 2000. Em 2015, "[...] os alunos de Portugal obtiveram pontuações significativamente superiores às médias da OCDE" (OCDE, 2015, p. 9-11). Os resultados apresentados por este órgão no que diz respeito aos índices de aproveitamento referentes a literacia matemática, obtidos desde os anos 2000 eram caracterizados como abaixo da média. Com isso, desencadearam-se definições de novos objetivos educativos e a adoção de novas estratégias curriculares que conduzissem à inversão dos resultados.

Todavia, o fato de alcançar o êxito e a elevação dos resultados quantitativos expressos pelos índices de avaliação não são suficientes para afirmar que houve uma melhora qualitativa nos níveis de aprendizagem lógica no tocante a criação e projeção emocional, social e cognitiva, de modo que as competências não se restringissem no atendimento exclusivo às demandas das políticas econômicas, mas que convergissem aos reclamos das políticas sociais. A par dessa situação, o Governo Português tem investido em políticas públicas educacionais e sociais, reformulando o currículo da Pré-Escola (MINISTÉRIO DA EDUCAÇÃO [ME], 2016). No entanto, face às novas exigências voltadas para uma qualidade na educação, faz-se um investimento na reestruturação curricular, tendo como objetivo principal a elevação dos índices de aproveitamento.

${ }^{2}$ As avaliações são provas para mensurar os conhecimentos, aplicadas de 3 em 3 anos.

${ }^{3}$ O PISA tem a função de identificar a tendência dos resultados obtidos em cada ciclo; a OCDE, uma organização internacional com o objetivo promover políticas em prol do desenvolvimento econômico e social visando ao bem-estar das pessoas. 
A educação da infância não ficou de fora, pois o governo Português acredita que os investimentos sociais e económicos devem ser a partir da base. Em função dessas questões citadas, o governo tornou a educação alvo de investimento para poder competir e empreender no mercado, estando esta na via de uma "racionalidade econômica" do sistema Neoliberal. A educação se tornou um produto ou melhor, um serviço para a comunidade, em que atualmente o foco de investimento inicia na infância para ter uma melhora no desempenho do acadêmico, para que no futuro possam ter condições e competência para "competirem eficientemente e eficazmente" (APPLE, 1998, p. 30)

Nessa perspectiva, o currículo está diretamente associado a uma política neoliberal, em que o conhecimento está voltado para os resultados de eficiência e qualidade dos sistemas educativos. Os jovens terão que ser capacitados para apreender e interpretarem os mais diversos tipos de textos, de resolverem problemas matemáticos e solucionarem desafios científicos (CARVALHO, 2011, p. 49). Diante das orientações da OCDE, os sistemas educativos devem desenvolver "competências para a vida" voltando a cultura educacional para a "economia baseada no conhecimento", em que a OCDE acaba por monitorar esta qualidade educacional (CARVALHO, 2011, p. 49-50).

A adesão a esse programa iniciou em 1999, assumindo o pacto educativo para o futuro em que pretendia assumir uma discussão pública em prol de novas orientações programáticas educativas, aliado a isso o PISA é utilizado para medir e produzir indicadores na avaliação de desempenho dos alunos do ensino básico e fundamental. Essas avaliações ocorrem de 3 em 3 anos, com ênfase em diferentes áreas do conhecimento da Leitura, Matemática e Ciências (CARVALHO, 2011, p. 108-16).

Em Portugal, essas mesmas preocupações já têm se alargado na educação da infância, em que as políticas públicas propõem novas respostas às condições sociais e económicas e

[...] compartilham de um mesmo vocabulário: promover o desenvolvimento, garantir a prontidão para aprender e a disposição para a escola; melhorar o desempenho escolar; e fazer uma intervenção precoce em crianças consideradas carentes, em risco ou outra forma de desvantagem, [...] ou seja, estabelecem uma linguagem da qualidade. (DAHLBERG; MOSS; PENCE, 2003, p. 10). 
Para as políticas públicas, a criança e a institucionalização da infância são investimentos futuros em que a criança assume o estatuto de ser social, que são definidos politicamente, a criança se tornou uma cidadão do amanhã, como diz Sarmento (2011, p. 589- 91), "não é mais da criança que a escola se ocupa, e sim do aluno, criança-aluno, desencadeando para uma perspectiva do ofício do aluno [...] em que este deverá inserir-se em uma cultura escolar estabelecida que Ihe exige e autonomia, eficiência e aprendizagem". Nessa perspectiva, a primeira infância Portuguesa também se torna objeto das culturas escolares, tendo que seguir as regras estabelecidas pelas políticas governamentais.

Portugal não foge à regra. Os efeitos desses processos têm provocado mudanças nas últimas duas décadas, nomeadamente na adopção de políticas de avaliação das escolas, com o objetivo de validar um determinado currículo de modo a que assegure a qualidade do sistema educativo, por meio de um conjunto de dispositivos legais.

As avaliações, em Portugal, seguem os critérios estabelecidos pelo PISA, as quais apontam uma evolução nos resultados, de maneira positiva, ano a ano, desde o ano 2000. Os resultados apresentados por esse órgão no que diz respeito aos índices de aproveitamento referentes à literacia matemática, obtidos desde os anos 2000, eram caracterizados como abaixo da média. Com isso, a OCDE encadeou novas definições e objetivos educativos bem como a adoção de novas estratégias curriculares que conduzissem à inversão dos resultados, o que veio a verificar-se em 2015, em que "[...] os alunos de Portugal obtiveram pontuações significativamente superiores às médias da OCDE" (OCDE, 2015, p. 9-11).

Todavia, quanto ao fato de alcançar o êxito e a elevação dos resultados quantitativos expressos pelos dados do PISA, estes índices de avaliação não são suficientes para afirmar que houve uma melhora qualitativa nos níveis de aprendizagem lógica no tocante a criação e projeção emocional, social e cognitiva, de modo que as competências não se restringissem ao atendimento exclusivo das demandas da política econômicas, mas que convergissem aos reclamos das políticas sociais.

A par dessa situação, o Governo Português tem investido em políticas públicas educacionais e sociais, reformulando o currículo e ampliando o ${ }^{4}$ tempo

\footnotetext{
${ }^{4}$ O Despacho n. 12.591/2006 assinala "urgência de adaptar os tempos de permanência das crianças nos estabelecimentos de ensino às necessidades das famílias". A outra questão ressaltada no dito despacho a respeito da implementação da escola tempo integral, foi com o intuito
} 
do aluno dentro da escola. É nesse contexto que a investigação se enquadra, procurando compreender influências de políticas internacionais harmonizadas com interesses económicos neoliberais nas políticas educacionais portuguesas orientadas para a Educação Pré-escolar. Por essa razão, consideramos pertinente construir um olhar particular sobre o processo de institucionalização da Educação Pré-escolar em Portugal, partindo de um olhar mais global sobre a institucionalização da Educação de Infância, destacando, a seguir, algumas políticas curriculares implementadas desde 1979.

\section{A INSTITUCIONALIZAÇÃO DA EDUCAÇÃO DA INFÂNCIA E POLÍTICAS CURRICULARES PARA A EDUCAÇÃO PRÉ-ESCOLAR EM PORTUGAL}

\subsection{A institucionalização da Educação da Infância}

A institucionalização da educação da infância está associada às transformações ocorridas na sociedade moderna; esse processo também é visível nas diferentes instituições sociais como a escola e a família, sendo esta última afetada com a crescente participação da mulher no mercado de trabalho (TOMÁS, 2007). Corsaro (2011), nessa linha, coloca que as famílias foram obrigadas a "recorrer a instituição de ensino, como as creches" na expectativa que esses espaços institucionais os substituiriam nos cuidados diários dos seus filhos, na formação e transmissão de valores que favoreçam a socialização e, sobretudo, a instrução para garantir a ascensão económica e social (CORSARO, 2011, p. 16).

Este é um dos exemplos que esclarece como a condição da infância é afectada pelas transformações da demografia e estrutura familiar ocorridas na sociedade e em que a institucionalização das crianças as obriga a fazer parte de grupos de pares criados "artificialmente", com base em idades semelhantes (CORSARO, 2011, p. 43). Daí que a crescente frequência, pelas crianças, dessas instituições tenha consequências na construção das suas experiências da infância e na construção das experiências educativas pelos próprios atores sociais.

O processo de institucionalização da Educação de Infância ocorreu em consequência das transformações ocorridas na sociedade e com a finalidade de

de promover o sucesso escolar e aumentar o índice de conhecimentos, ou seja, "promover o sucesso escolar futuro". 
promover a proteção e cuidados da/às crianças e como suporte às mães trabalhadoras (VILARINHO, 2000). Como sublinha Cardona (1997), na transição do século XIX para o início do século XX, "o pensar na guarda das crianças começou então a ser uma necessidade em relação à qual foi preciso encontrar resposta” (CARDONA, 1997, p. 25). O surgimento das primeiras instituições ao longo do tempo, está em conformidade com a realidade sociocultural e económica do país. No entanto houve um crescimento maior e o reconhecimento público com referência à importância de instituições de educação da infância após a revolução de 1974.

A partir do contexto de 1979, com a criação da rede Pública da Educação Pré-escolar, determina-se a institucionalização da Educação Infância em Portugal, dando visibilidade à crescente implantação da rede pública de Jardim de Infância.

\subsection{Políticas Curriculares para a Educação Pré-Escolar 1979-1997}

Como se referiu, a institucionalização da educação Pré-Escolar em Portugal ganha crescente visibilidade da Rede Pública da Educação Pré-Escolar, em 1978/79 e com a publicação dos Estatutos dos Jardins de Infância (Decreto-Lei n. 542/79). A criação da rede pública de Educação Pré-escolar está, como nota Vilarinho (2000, p. 136), associada "à ideia de democratização do ensino, do princípio de igualdade em educação e, ao direito de as crianças usufruírem uma educação laica e gratuita".

O Decreto-Lei n. 542/79 institui os Estatutos do Jardim de infância da rede pública do Ministério da Educação e enfatizava a ação voltada para as necessidades da família e para a inclusão social, conforme é expresso: A educação pré-escolar é o início de um processo de educação permanente a realizar pela ação conjugada da família, da comunidade e do Estado, tendo em vista: a) Assegurar as condições que favoreçam o desenvolvimento harmonioso e global da criança; b) Contribuir para corrigir os efeitos discriminatórios das condições sócio culturais no acesso ao sistema escolar; [...] (Artigo 1.ํ)

Constituem critérios genéricos a observar na implantação da rede do sistema público de educação pré-escolar:

a) Atender às características específicas de determinadas zonas, nomeadamente daquelas onde se verifiquem taxas elevadas de população ativa feminina; b) Favorecer as zonas mais carenciadas de equipamentos sociais e culturais, nomeadamente rurais e suburbanas; c) Considerar as iniciativas de grupos de cidadãos ou de entidades colectivas de natureza económica, social ou cultural. (Art. 7으, ponto 2). 
Percebe-se também que esse decreto lei tem como finalidade constituir-se numa medida de complementaridade da família, o que parece apontar para uma conceção de educação compensatória. Quanto à frequência de instituições destinadas para crianças na faixa-etária de 3 a 5 anos, é enunciado, no artigo 20으 do referido decreto, respetivamente, que "A frequência dos jardins de infância do sistema público tem carácter facultativo" e art. 21ㅇqu "Poderão frequentar os jardins de infância do sistema público as crianças com idades compreendidas entre os 3 anos e a idade legal de ingresso no ensino primário"

Em 1986, é publicada a Lei de Bases do Sistema Educativo (LBSE), Lei n. 46/86 de 14 de outubro. Nela é estabelecido, e reforçado, que a Educação Préescolar tem como objetivo constituir-se num espaço de educação concomitante às famílias. Estabelece também que o Estado português, por meio do Ministério da Educação, administrará a educação pré-escolar.

Prevê ainda que a família tem a responsabilidade de encaminhar a criança para a Educação pré-escolar, conforme os artigos 2ำ e 5ㅇ-8:

Todos os portugueses têm direito à educação e à cultura, nos termos da Constituição da República (Artigo 2ㅇ); [...] A frequência da educação pré-escolar é facultativa, no reconhecimento de que à família cabe um papel essencial no processo da educação pré-escolar. (Artigo 5-o 8).

Como se depreende, o governo assegura a garantia do direito à educação, bem como "a garantia de uma permanente ação formativa orientada para favorecer o desenvolvimento global da personalidade, o progresso social e a democratização da sociedade" (Artigo 1으). Este artigo assegura o direito a igualdade de acesso e sucesso escolar.

No que tange aos objetivos e orientações pedagógicas para a Educação Pré-escolar, no Artigo 5으, se nota certa preocupação, ainda que não totalmente explícita, sobre os conteúdos e que estes deverão estar contextualizados ao meio familiar. Estabelecendo aqui uma relação com o foco em estudo, chama-nos atenção o item "f", que salienta uma preocupação com referência à estimulação lúdica, e ao desenvolvimento de capacidades de expressão e comunicação da criança, e a sua imaginação criativa. Olhando para a globalidade dos objetivos, fica explícita a valorização de enfoques que parecem apontar uma pedagogia centrada fundamentalmente "no cuidar" e na inculção de hábitos de higiene e defesa da saúde. Ainda no Artigo 5o é elencado a preocupação "para a estabilidade e 
segurança afectivas da criança e incutir hábitos de higiene e de defesa da saúde pessoal e colectiva" (LBSE, n. 46/86 de 14 de outubro)

O Decreto-Lei n. 46/86 vai ao encontro de uma lógica curricular que aponta para o desenvolvimento integral e para a atenção às particularidades e necessidades de cada criança com a intencionalidade de favorecer e estimular todas as suas potencialidades e contribuir para a sua formação global.

Percebe-se, nessa orientação da política educativa, um reconhecimento da Educação Pré-Escolar como um meio privilegiado para reduzir as desigualdades sociais e favorecer o desenvolvimento das crianças. Essa visão é apoiada por Formosinho (1994, p. 12) quando refere que "a educação pré-escolar de qualidade é um dos maiores investimentos que uma sociedade pode fazer".

Após dez anos da publicação da LBSE, houve a mudança de governo e com ele novas demandas políticas, surgindo assim, em 1997, as Orientações Curriculares para a Educação Pré-Escolar (OCEPE), com o Despacho n. 5220/97 do Diário da República n. 178, II. Com essas novas demandas da política e num esforço político de promoção da Educação Pré-Escolar, esta foi consignada como primeira etapa da Educação Básica. À data, a diretora do departamento de Educação Básica, Teresa Vasconcelos, deixou claro essa ideia no documento, ao estabelecer que as OCEPE tinham, como princípio geral, a "educação pré-escolar como a primeira etapa da educação básica no processo de educação ao longo da vida, sendo complementar da ação educativa da família, com a qual deve estabelecer estreita relação, favorecendo a formação e o desenvolvimento equilibrado da criança e sua plena inserção na sociedade como ser autônomo, livre e solidário" (ME, 1997, p. 15). As OCEPE de 1997 seriam um "ponto de apoio" para a educação da infância, e uma estrutura de suporte para uma educação que se desenvolve ao longo da vida; um alicerce de uma vida social, emocional e intelectual que se pauta pelo princípio da igualdade de oportunidades para todas as crianças e, como tal, como contexto de realização de cidadania (ME, 1997, p. 9). Nota-se a importância atribuída à educação global da criança, seu desenvolvimento harmonioso e a parceria com a família.

Essa década foi marcada por diversas transformações, principalmente, para educação da infância, tanto a nível da organização curricular como para formação dos/as educadores/as. Uma das referências descritas nas OCEPE remete ao planejamento do educador da infância, salientando a importância do reconhecimento 
das crianças como sujeitos do processo educativo. Nesta o educador está como responsável [...] na organização do ambiente educativo, a continuidade e a intencionalidade educativas entre as áreas de conteúdo estabelecidas, valorizando a sua articulação, na sua diversidade e cooperação. Trata-se de alargar intencionalmente as situações de comunicação em diferentes contextos, com diversos interlocutores, conteúdos e objectivos que permitam às crianças dominar progressivamente a comunicação como emissores e como receptores (ME, 1997, p. 68).

As OCEPE elencam princípios que apoiam o educador/a em sua prática, a fim de "conduzir o processo educativo a desenvolver com as crianças» (ME, 1997, p. 13), os quais apontam para a articulação dos seguintes fundamentos: o desenvolvimento e aprendizagem como vertentes indissociáveis; o reconhecimento da criança como sujeito do processo educativo - o que significa partir do que a criança já sabe e valorizar os seus saberes como fundamento de novas aprendizagens; a construção articulada do saber - o que implica que as diferentes áreas a contemplar não deverão ser vistas como compartimentos estanques, mas abordadas de uma forma globalizante e integrada; a exigência de resposta a todas as crianças - o que pressupõe uma pedagogia diferenciada, centrada na cooperação, em que cada criança beneficia do processo educativo desenvolvido com o grupo (ME, 1997, p. 13-9).

Os princípios acima destacam pontos orientadores para as/os educadoras/es a fim de promoverem a instrução e o reconhecimento da participação das crianças no processo educativo e a valorização dos seus saberes como fundamento de novas aprendizagens. Outros conceitos como: igualdade de oportunidades, aprender a aprender, caráter lúdico, cuidar e o cuidado ético, partir do que a criança sabe, e educação para a cidadania estão elencados nas OCEPE, percebendo-se uma valorização da criança no processo educativo, bem como a valorização do caráter lúdico (ME, 1997).

Especificamente, em relação ao currículo, as OCEPE (ME, 1997) estabelecem três grandes Áreas de Conteúdo: Área de Formação Pessoal e Social, Área de Conhecimento de Mundo e a Área de Expressão e Comunicação que têm por objetivo referenciar o planejamento dos/as educadores/as. A estes/as cabe assegurar "a organização do ambiente educativo, a continuidade e a intencionalidade educativas nessas áreas de conteúdo estabelecidas, valorizando a sua articulação, na sua diversidade e cooperação" (ME, 1997). 
As Áreas de Conteúdo deverão ser levadas em consideração no planejamento e avaliação das aprendizagens das crianças e ter em conta "os âmbitos de saber, com uma estrutura própria e com pertinência sociocultural, que incluem diferentes tipos de aprendizagem, não apenas conhecimentos, mas também atitudes, disposições e saberes- fazer" (ME, 1997, p. 47).

É importante destacar o lugar que o domínio da linguagem matemática assume nas OCEPE. É indicado que aquele domínio tem um papel na "estruturação do pensamento, as suas funções na vida corrente e sua importância nas aprendizagens futuras determina a atenção que lhe deve ser dada na educação pré-escolar, cujo quotidiano oferece múltiplas possibilidades de aprendizagens matemáticas" (ME, 1997, p. 73). Em termos curriculares, no domínio da matemática, estão elencados alguns conteúdos a serem trabalhados como: números, encontrar e formar padrões, tempo espaço, utilização de materiais, medir, pesar, resolução de problemas (ME, 1997, p. 73-8). Ainda que subtil a abordagem dos conteúdos a serem trabalhados, mesmo não muito detalhados, estes denotam um movimento no sentido de uma preparação futura, orientada para o sucesso educativo o que parece deixar transparecer uma concepção escolarizada da Educação de Infância.

Quanto às funções do/a educador/a, de acordo com as OCEPE, as intencionalidades educativas expressas salientam a observação e o planeamento, de acordo com o grupo e com cada criança para atender às especificidades do contexto familiar e social, promovendo aprendizagens significativas (ME, 1997, p. 25-8).

A proposta da área matemática sugere que o educador/a recorra a metodologias ativas priorizando a realidade das crianças,

[...] partir das situações do quotidiano para apoiar o desenvolvimento do pensamento lógico-matemático, intencionalizando momentos de consolidação de noções matemáticas. [...] importa que o educador proponha situações problemáticas e permita que as crianças encontrem as suas próprias soluções, que as debatam com outra criança, num grupo pequeno, ou mesmo com todo o grupo, apoiando a explicação do porquê da resposta e estando atento a que todas as crianças tenham oportunidades de participar no processo de reflexão. (ME, 1997, p. 73-8).

Nota-se, nas funções atribuídas ao educador/a, uma conceção de educador como "gestor do currículo" (ME, 1997, p. 17), como alguém que instiga as crianças a serem autônomas, a aprender a aprender, a terem autoconfiança, a desenvolverem competências e a serem criativas e reflexivas. 
Neste olhar sobre políticas curriculares para a Educação Pré-Escolar em Portugal vislumbram-se novas demandas políticas que podem, de algum modo, ser associadas às avaliações publicadas pelo PISA e que têm repercussões em todo o sistema educativo português e também particular na Educação Pré-Escolar, levando à reformulação das OCEPE implementadas em 1997.

\subsection{Currículo e a Reformulação Curricular da Educação Pré-Escolar em 2016}

É inevitável pensar na função do currículo no processo de formação educacional das crianças em idade pré-escolar sem ter em conta as OCEPE, já focadas no ponto anterior, e a sua reformulação, em 2016, de que nos ocuparemos neste ponto do trabalho. Com efeito, as OCEPE, corporizam a política pública para Educação de Infância no tocante a objetivos curriculares e de aprendizagem, a estratégias, a planeamentos e a práticas pedagógicas a serem seguidos e desenvolvidos nos espaços institucionais.

Para a discussão que pretendemos, ser feita neste ponto importará abrir um parêntesis para atentar em conceções de currículo e refletir sobre conceções curriculares que informam as mais recentes OCEPE. Morgado e Paraskeva (2000, p. 5) sustentam uma perspectiva ampla de currículo quando argumentam que "o currículo denuncia um conjunto de intencionalidades, vertidas nas políticas educativas e, em geral, nas políticas curriculares". Por seu lado, Pacheco (2001, p. 15-7) define o currículo como "um conjunto de conteúdos e materiais a serem ensinados" em um planejamento organizado a fim de alcançar a aprendizagem pretendida para com os alunos. Num entendimento mais amplo, Morgado, (2004, p. 18) define currículo como um "conjunto de aprendizagens valorizadas socialmente, e como uma construção inacabada, resultante da participação de todos os intervenientes do processo educativo", o que pressupõe que o currículo poderá ser construído com o apoio da comunidade e dentro das suas necessidades locais, um currículo localizado e não central.

Adotar um conceito de currículo como um conjunto de conteúdos não seria relevante para a educação da infância, tendo em conta os objetivos previstos para esse nível de formação e a que já nos referimos. Uma proposta alternativa será pensar o desenvolvimento de aprendizagens a partir de projetos pedagógicos condizentes com a cultura local, e numa orientação educacional inclusiva. Barbosa 
(2009) defende, dentre outras propostas, a decisão irrefutável de uma política educacional voltada para os interesses das crianças. Sugere, assim que um projeto educacional não é apenas uma escolha entre um ou outro modelo de vida. O processo educacional, principalmente aquele presente nos sistemas de ensino, é uma decisão política acerca do futuro de uma sociedade. É preciso pensar projetos educacionais que possam, em sua complexidade, dar conta tanto das necessidades de segurança, proteção e pertencimento, quanto das de liberdade e autonomia (BARBOSA, 2009, p. 12).

Esta autora sustenta uma concepção de um currículo voltado para a criança e para o estabelecimento de relações, entre si e o outro, que possibilitem construir, articular e produzir aprendizagens no seu percurso institucional. Barbosa (2009) também sugere que na educação infantil a criança possa conviver em comunidade precisando, assim, de exercitar nas relações cotidianas a importância da cooperação e colaboração entre os seus integrantes, de maneira que a consciência da diversidade seja um aprendizado, aprender a ver o universo a partir da perspectiva do outro.

É no quadro destas ideias que Zabalza (2011) adverte para necessidade de um currículo com maior flexibilidade, que respeite a diversidade de interesses, a capacidade das crianças e que consiga responder as suas solicitações. Retomando agora as OCEPE (ME, 2016) desde a introdução sinalizam, que o currículo se desenvolve com articulação plena das aprendizagens, em que os espaços são geridos de forma flexível, em que as crianças são chamadas a participar ativamente na planificação das suas aprendizagens, em que o método de projeto e outras metodologias ativas são usados rotineiramente, em que se pode circular no espaço de aprendizagem livremente (ME, 2016, p. 4). É sugerido, portanto, a participação das crianças no planejamento, adotando perspetivas de um currículo mais flexível na aprendizagem das crianças (ZABALZA, 2011).

Importante sinalizar nestas OCEPE, que a criança é vista como um sujeito ativo, agentes sociais no processo, "o desenvolvimento e aprendizagem como vertentes indissociáveis no processo de evolução da criança; reconhecimento da criança como sujeito e agente do processo educativo; exigência de dar resposta a todas as crianças e construção articulada do saber" (ME, 2016, p. 8-10).

Um dos objetivos deste currículo é melhoria da qualidade da ação educativa e reportando para uma intencionalidade educativa caracterizada pela intervenção do educador/a junto com as crianças, assentando em uma abordagem sistémica 
ecológica que "assenta no pressuposto de que o desenvolvimento humano constitui um processo dinâmico de relação com o meio, em que o indivíduo é influenciado, mas também influencia o meio em que vive" (ME, 2016, p. 21).

Também vale referir as outras dimensões que estão interligadas, especialmente, nas áreas de conteúdo e na promoção das aprendizagens. Neste documento também foi incluído a intencionalidade educativa para construir e gerir o currículo, observar, registrar e documentar, planear, agir e avaliar. O documento realça a importância da observação para efetivar o planeamento voltado na aprendizagem da criança. Nestes documentos também realçam as outras funções que o educador deverá levar em conta as características da criança, criando oportunidades que lhe permitam realizar todas as suas potencialidades; considera a sua família e sua cultura na sua ação educativa; parte das experiências da criança., e valoriza os seus saberes como fundamento de novas aprendizagens; - escuta e considera as opiniões da criança, garantindo a sua participação nas decisões relativas ao seu processo educativo; estimula as iniciativas da criança, apoiando o seu desenvolvimento e aprendizagem: aceita e valoriza cada criança reconhecendo os seus progressos; -tira partido da diversidade para enriquecer as experiências e oportunidades de aprendizagem de todas as crianças;- adota práticas pedagógicas diferenciadas, que respondam às características individuais de cada criança e atendam as suas diferenças;- promove o desenvolvimento de um sentido de segurança e autoestima em todas as crianças;- estimula o brincar, através de materiais diversificados, apoiando as escolhas, explorações e descobertas da criança;- aborda as diferentes áreas de forma globalizante e integrada;- estimula a curiosidade da criança criando condições para que aprenda a apreender (ME, 2016, p. 12).

Na nova estruturação curricular de 2016 é contemplado três seções: Enquadramento Geral que são orientações globais do trabalho pedagógico, que se dividem em: fundamentos e princípios da pedagogia para a infância; intencionalidade educativa - construir e gerir o currículo; e organização do ambiente (ME, 2016, p. 5).

Após esta orientação, o currículo foi dividido em Área de Conteúdo, Área de Formação Pessoal e Social; Área do Conhecimento de Mundo e Área de Expressão e Comunicação, as quais se constituíam como área básica, uma vez que engloba diferentes formas de linguagem e a única que comporta diferentes domínios. Um 
destes, é o Domínio da Matemática que contém componentes e aprendizagens a promover, especifica os conteúdos que terão que ser trabalhados, como: Números e operações, Organização e tratamento de dados, Geometria e medida, Interesse e curiosidade pela Matemática (ME, 2016, p. 76-84).

A reformulação das Orientações Curriculares (ME, 1997), também enfatiza o papel dos educadores na promoção do desenvolvimento das competências das crianças, um exemplo, são as competências matemáticas, esclarecedoras para o /a educador/a, em que educador/a deverá proporcionar experiências diversificadas e desafiantes, apoiando a reflexão das crianças, colocando questões que lhes permitam ir construindo noções matemáticas e propondo situações problemáticas em que as crianças encontrem as suas próprias soluções e as debatam com as outras (ME, 2016, p. 74).

Observa-se uma certa tendência por parte das Orientações Curriculares de 2016 que está voltada para uma cultura escolar e ofício do aluno, visto pela quantidade de conteúdos a exemplo da matemática, que o educador/a deverá dar conta de transmitir às crianças. Percebe-se que as políticas educacionais Portuguesas "compartilham de um mesmo vocabulário: promover o desenvolvimento, garantir a prontidão para aprender e a disposição para a escola; melhorar o desempenho escolar e fazer uma intervenção precoce [...]" (DAHLBERG; MOSS; PENCE, 2003, p. 10).

A qualidade está voltada para os objetivos dos adultos e foram criadas escolas públicas visando as políticas públicas voltadas para satisfazer o mercado, e a criança neste caso, não é ouvida, ela é pensada e vista como um "vir a ser", no que ela poderá contribuir para a qualidade do mercado e do consumo. Neste sentido, a criança não está sendo ouvida, ela é anulada e, conforme Sarmento (2011), a criança "morre", [...] enquanto sujeito concreto, com saberes e emoções, aspirações, sentimentos e vontades próprias, para dar lugar ao aprendiz, destinatário da acção adulta, agente de comportamentos prescritos, pelo qual é avaliado, premiado ou sancionado. A escola criou uma relação particular com o saber, uniformizando o modo de aquisição e transmissão do conhecimento, para além de toda a diferença individual, de classe ou de pertença cultural (SARMENTO, 2011, p. 589).

Para as políticas públicas educacionais, a Educação Pré-escolar parece estar cada vez mais ao serviço da economia globalizada e política neoliberal em que a "criança assume o estatuto de ser social, objecto de um processo intencional de 
transmissão de valores e saberes comuns, politicamente definidos, e destinatário do objectivo das políticas públicas" (SARMENTO, 2011). A criança se tornou um cidadão do amanhã definido pelos governantes e, como diz Sarmento, "não é mais da criança que a escola se ocupa, e sim, do aluno, criança - aluno, desencadeando para uma perspectiva do ofício do aluno [...] em que este deverá inserir-se em uma cultura escolar estabelecida que the exige autonomia, eficiência e aprendizagem". A criança aos poucos vai se moldando em conformidade a estrutura da escola, tendo que ajustar- se a regras, a disciplina do corpo e da mente. A política pública educacional está mais preocupada com o que a criança poderá contribuir futuramente do que respeitá-la como criança. A criança, aos poucos, está a perder o direito de viver a infância e o direito de brincar, para ter que se dedicar ao ofício do aluno (SARMENTO, 2011, p. 590-1).

Percebe-se, que, cada vez mais, a educação da infância tem estado na agenda política do governo Português, o mesmo aposta em um currículo voltado para cultura escolar. Aos poucos, a criança está perdendo o direito de vivenciar a sua cultura lúdica, ou melhor o seu ofício de criança, a partir para o ofício de aluno e ter que se moldar as novas OCEPE. Esta preocupação com relação à aprendizagem das crianças tem ultimamente se traduzido não só nas políticas públicas, mas é possível ser percebido na formação dos educadores e em um planejamento voltado para o cumprimento das OCEPE.

O Governo apostou num currículo educacional, ampliando não só o tempo de permanência nas escolas, coforme o Despacho n. 12.591/2006, mas, sobretudo, implantou um currículo com carga intensa e exaustiva de atividades escolares em detrimento do tempo do brincar e do experienciar aprendizagem e o desenvolvimento cognitivo por meio de atividades lúdicas. Nesse compasso, o governo investiu em um currículo por competência, na possível garantia de que a transferência do saber e do saber-fazer trabalhados na escola pudesse ser utilizada para o uso social dos cidadãos escolarizados, desse modo, seria assegurado o progresso da vida pessoal, social e económica das pessoas.

Um dos principais argumentos da nova estruturação do currículo é o de que é necessário investir em longo prazo, começando por intervir, pedagogicamente, nas primeiras experiências das crianças, quando estas estarão desenvolvendo as competências e a aquisição dos novos conhecimentos. Conforme as OCEPE (ME, 16) "agir cedo para ter melhores resultados no futuro e garantir uma sociedade em 
que todos têm as mesmas oportunidades, potencializando, através da educação, para que tenhamos uma sociedade mais justa e mais coesa" (ME, 2016, p. 4). O secretário de estado da educação, João Costa, salienta ainda que "uma educação pré-escolar de qualidade é um preditor de sucesso na escolaridade e na qualidade de vida dos jovens e dos adultos" (ME, 2016).

A preocupação com relação à aprendizagem das crianças tem ultimamente se traduzido na formação dos educadores e em um planejamento voltado para o cumprimento das OCEPE. Este movimento é percebido nas pesquisas académicas que datam, principalmente, no período de 2006 a 2016.

\subsection{A produção do conhecimento académico entre 2006 e 2016 sobre a matemática na educação na infância}

Ao que se refere as pesquisas de dissertações, teses de doutoramento, artigos e, principalmente, relatórios de estágio, realizadas nos repositórios acadêmicos no período de 2006 a 2016, haja vista, a não menor preocupação com relação às aprendizagens das crianças se comparada com a formação de professoras/es, a maioria das pesquisas foram provenientes dos Institutos de Educação, onde há a formação inicial de educadores de infância.

Constatam-se nos relatórios de estágio apresentados nesse período, nos Institutos Politécnicos de Educação do país, que os/as estudantes têm direcionado seus projetos com ênfase no Currículo da Pré-Escola. Pesquisas em ambientes digitais realizadas nos Repositoriuns das Faculdades e dos Institutos de Educação de Portugal, por meio de índices de busca 'matemática na educação infantil' ou 'matemática, brincadeira e infância', apontam a prevalência em temas acerca da prática pedagógica do/a professor/a ou para a ampliação do conhecimento da criança da educação da infância, o currículo nesse nível de escolarização também tem sido privilegiado nos trabalhos acadêmicos de conclusão de curso, principalmente os relatórios de estágio.

Somente em um Repositórium académico foi encontrada uma pesquisa na modalidade artigo intitulada "O raciocínio multiplicativo em crianças do pré-escolar" (MAMEDE; SOUTINHO, 2011). A dita pesquisa versa analisar 6 crianças em um Jardim de Infância, a fim de destacar os desempenhos de crianças, de 4 aos 6 anos, que ainda não receberam instrução formal, de modo que sinaliza as estratégias utilizadas para solucionarem problemas que envolvem o raciocínio 
multiplicativo. Os resultados apontam que as crianças resolveram as questões de raciocínio multiplicativo antes que tais operações fossem ensinadas, formalmente, na escola, utilizando apenas o seu conhecimento matemático informal.

As demais pesquisas realizadas carenciavam o foco sob a percepção das crianças, tão pouco as crianças como atores sociais e produtoras do conhecimento. O foco estava direcionado à prática pedagógica, ao planejamento da educadora e, sobretudo, na contemplação do currículo, ficou clara a preocupação do adulto em contemplar as proposições da Orientação Curricular nos seus planeamentos e de uma aprendizagem voltada mais para um ofício de aluno, e não para o oficio da criança.

A partir dos dados levantados, percebe-se a carência de pesquisas que valorizam a criança enquanto ator social na construção do conhecimento matemático entre seus pares na sua cultura lúdica. Dessa forma, com este artigo, coloca-se como uma importante contribuição na ampliação desses estudos, pois a pesquisa é movida pela crença de que a organização social do Jardim de Infância é um lugar privilegiado para as experiências entre as crianças e espaços de brincadeiras entre seus pares, uma vez que esses espaços privilegiam a construção identitária da criança como indivíduo.

\section{CONSIDERAÇÕES FINAIS}

Ao estarmos preocupados com relação aos aspectos e efeitos que a globalização ou o neoliberalismo acarretam no cotidiano escolar, é importante também observarmos o efeito que estes têm ocasionado perante o currículo, nas práticas dos profissionais da educação e na vida das crianças. Uma forma visível desse efeito pôde-se perceber nas reformulações curriculares da Pré-Escola ocorridas em 2016, em que este está voltado para uma aprendizagem ao longo da vida e na ampliação de conteúdos, nomeadamente a matemática. Também podemos perceber as mudanças em todos os níveis da educação, devido às sucessivas avaliações externas, em que cada vez mais Ihes exigem competências e qualidade, regulando o gerenciamento do currículo na sua forma de organização e conteúdos a serem ensinados, principalmente a sua avaliação quanto ao cumprimento de metas a serem atingidas.

Por mais que o plano curricular centralizado padronize os conteúdos a serem ensinados, o educador e professor com sua autonomia em sala poderão recontextualizar os saberes importantes para seus alunos, conforme (CORTESÃO; 
STOER, 2003, p. 201-2) “domínio do conhecimento sobre os alunos e das suas necessidades e interesses, do conhecimento profundo das características do currículo, [...] abre ao professor a possibilidade de recontextualizar os saberes eleitos como importantes pelo currículo", Isso proporciona às crianças e às professoras /res possíveis novos desafios de aprendizagem criando estratégias para sobreviverem a tantas normativas impostas pelas exigências administrativas por parte de seus governantes, bem como, um currículo voltado à padronização de competências de aprendizagem tendo que os alunos se adequarem às novas exigências do mundo neoliberal e globalizado.

\section{REFERÊNCIAS}

APPLE, Michael et al. Paulo Freire: política e pedagogia. Porto, Portugal: Porto Editora, 1998.

BARBOSA, Maria C. S. Práticas cotidianas na educação infantil: bases para a reflexão sobre orientações curriculares. Brasília: MEC, 2009. Disponível em: http://portal.mec.gov.br/ dmdocuments/relat_seb_praticas_cotidianas.pdf. Acesso em: 26 nov. 2017.

CARDONA, Maria João. Para a história da educação de infância em Portugal. O discurso oficial (1834-1990). Porto, Portugal: Porto Editora, 1997.

CARVALHO, Miguel. O espelho do perito: inquéritos internacionais, conhecimento e política em educação- o caso do PISA. Vila Nova de Gaia, Portugal: Fundação Manuel Leão, 2011.

CORSARO,William A. Sociologia da Infância. Porto Alegre: Artimed, 2011.

CORTEZÃO, Luisa; STOER, Stephen R. A interface de educação intercultural e a gestão de diversidade na sala de aula. In: GARCIA, Regina L.; MOREIRA, Antonio F. (Org.). Currículo na contemporaneidade. Incertezas e desafios. São Paulo: Cortez, 2003. p. 189-208.

DAHLBERG, Gunilla; MOSS, Peter; PENCE, Alan. Qualidade na educação da Primeira Infância: perspectivas pós-modernas. Porto Alegre: Artmed, 2003.

DALE, Roger. Globalização e educação: demonstrando a existência de uma "cultura educacional mundial comum" ou localizando uma "agenda globalmente estruturada para a educação". Educação \& Sociedade, Campinas, SP, v. 25, n. 87, p. 423-60, maio/ago. 2004. Disponível em: http://www.scielo.br/pdf/es/v25n87/21464.pdf. Acesso em: 26 nov. 2016. 
DAVOK, Delsi Fries. Qualidade em educação. Avaliação. Campinas/Sorocaba, SP, v. 12, n. 3, p. 505-13, set. 2007. Disponível em: www.scielo.br/pdf/aval/v12n3/a07v12n3. Acesso em: 10 dez. 2017.

FORMOSINHO, João. Pareceres e recomendações: a educação pré-escolar em Portugal. Lisboa: Ministério da Educação/Conselho Nacional de Educação, 1994.

GIDDENS, Anthony. O mundo na era da globalização. Lisboa: Editorial Presença, 2000.

MAMEDE, Ema; SOUTINHO, Florbela. O raciocínio multiplicativo em crianças do préescolar. Braga, Portugal, 2011. Disponível em: http://repositorium.sdum.uminho.pt/ handle/1822/15499. Acesso em: 10 jul. 2017.

MINISTÉRIO DA EDUCAÇÃO. Orientações curriculares para a educação Pré-Escolar. Lisboa, 2016 (Colecção Educação Pré-Escolar; v. 1). Disponível em: https://www.dge. mec.pt. Acesso em: 10 jun. 2017.

MINISTÉRIO DA EDUCAÇÃO. Orientações curriculares para a educação Pré-Escolar. Lisboa, 1997. (Colecção Educação Pré-Escolar; v. 1). Disponível em: https://www.dge. mec.pt. Acesso em: jun. 2017.

MORGADO, José C.; PARASKEVA, João M. Currículo: factos e significações. Porto, Portugal: Edições Asa, 2000. (Cadernos do CRIAP, n. 15).

MORGADO, José C. Manuais escolares: contributo para uma análise. Porto, Portugal: Porto Editora, 2004.

PACHECO, José A. Teorias curriculares: políticas, lógicas e processos de regulação regional das práticas curriculares. Conferência realizada no âmbito do Seminário "O Currículo Regional". Açores, Portugal, 2001. Disponível em: http://webs.ie.uminho.pt/jpacheco/ files/curriculoRegional.pdf. Acesso em: jun. 2017.

SARMENTO, Manuel. A reinvenção do ofício de criança. Atos de Pesquisa em Educação, Blumenau, SC, v. 6, n. 3, p. 581-602, set./dez. 2011. Disponível em: http://proxy.furb.br/ ojs/index.php/atosdepesquisa/article/view/2819/1825. Acesso em: 15 ago. 2017.

TOMÁS, Catarina. Globalização: do reflexo na infância à reflexão com as crianças. In: DORNELLES, Leni (Org.). Produzindo pedagogias interculturais na infância. Petrópolis, RJ: Vozes, 2007.

VILARINHO, Maria. Políticas de Educação Pré-escolar em Portugal. (1977-1997). Lisboa: Instituto de Inovação Educacional, 2000. 
ZABALZA, Miguel. Currículo: caminho da flexibilidade. Revista Educação. 2011. Disponível em: http://revistaeducacao.uol.com.br/textos/166/caminho-da-flexibilidade. Acesso em: 26 nov. 2016.

\section{Websites:}

http://iave.pt/np4/68.html. Acesso em: 15 mar. 2017. https://www.dge.mec.pt. Acesso em: 10 jun. 2017.

http://legisedu.sec-geral.mec.pt/. Acesso em: 10 jun. 2017. http://www.instituto-camoes.pt/. Acesso em: 17 mar. 2017. http://www.oecd.org/pisa/. Acesso em: 15 dez. 2017.

\section{Sobre as autoras:}

Silvani Kempf Bolgenhagen: Doutoranda Faculdade de Psicologia e Ciências da Educação da Universidade do Porto, Portugal. E-mail: silkbol@hotmail.com

Ariana Cosme: Doutora em Educação pela Faculdade de Psicologia e Ciências da Educação da Universidade do Porto, Portugal. Professora Auxiliar na Faculdade de Psicologia e Ciências da Educação da Universidade do Porto, Portugal. E-mail: ariana@fpce.up.pt

\section{Recebido em maio de 2018 Aprovado em outubro de 2018}


